\title{
Attribution Markers and Data Mining in Art Authentication
}

\author{
Barbara I. Łydżba-Kopczyńska ${ }^{1,2, *(D)}$ and Janusz Szwabiński ${ }^{3}$ (D) \\ 1 Faculty of Chemistry, University of Wrocław, F. Joliot-Curie 14, 50-383 Wroclaw, Poland \\ 2 Laboratory of Analysis and Non-Destructive Investigation of Heritage Objects, National Museum in Kraków, \\ 30-062 Krakow, Poland \\ 3 Hugo Steinhaus Center, Faculty of Pure and Applied Mathematics, Wrocław University of Science and \\ Technology, Wyb. Wyspiańskiego 27, 50-370 Wroclaw, Poland; janusz.szwabinski@pwr.edu.pl \\ * Correspondence: barbara.lydzba@chem.uni.wroc.pl
}

Citation: Łydżba-Kopczyńska, B.I.; Szwabiński, J. Attribution Markers and Data Mining in Art

Authentication. Molecules 2022, 27, 70.

https://doi.org/10.3390/

molecules 27010070

Academic Editors: Maria

Luisa Saladino and

Francesco Armetta

Received: 28 October 2021

Accepted: 20 December 2021

Published: 23 December 2021

Publisher's Note: MDPI stays neutral with regard to jurisdictional claims in published maps and institutional affiliations.

Copyright: (c) 2021 by the authors. Licensee MDPI, Basel, Switzerland. This article is an open access article distributed under the terms and conditions of the Creative Commons Attribution (CC BY) license (https:// creativecommons.org/licenses/by/ $4.0 /)$.

\begin{abstract}
Today's global art market is a billion-dollar business, attracting not only investors but also forgers. The high number of forged works requires reliable authentication procedures to mitigate the risk of investments. However, with the developments in the methodology, continuous time pressure and the threat of litigation, authenticating artwork is becoming increasingly complex. In this paper, we examined whether the decision process involved in the authenticity examination may be supported by machine learning algorithms. The idea is motivated by existing clinical decision support systems. We used a set of 55 artworks (including 12 forged ones) with determined attribution markers to train a decision tree model. From our preliminary results, it follows that it is a very promising technique able to support art experts. Decision trees are able to summarize the existing knowledge about all investigations and may also be used as a classifier for new paintings with known markers. However, larger datasets with artworks of known provenance are needed to build robust classification models. The method can also utilize the most important markers and, consequently, reduce the costs of investigations.
\end{abstract}

Keywords: authentications; paintings; data mining; analytical procedures; forensic analysis

\section{Introduction}

Since early 2000s, the fine art market has made significant progress exhibiting its dynamic characters, with a $1370 \%$ turnover growth rate over a 16-year period [1]. Artprice with the collaboration of its Chinese State partner AMMA (Art Market Monitor of Artron), reported that, in 2020, the art market fell $21 \%$ down to $\$ 10.57$ billion [2]. This was a surprisingly small contraction given the impact of the COVID-19 crisis on the art market as a whole (galleries, museums, fairs, etc.) [2]. Considering the above, it is not surprising that the number of fakes, forgeries and copies emerging on the art market in recent years is significant and fast growing [3,4]. Fine art authentication is a lucrative business. The opinions of well-established experts are rarely challenged [3], since forgers, by nature, prefer anonymity. However, the number of cases where confirmation of art authenticity has turned into a nightmare for an expert is on the rise. The unique story of Han van Meegeren, who is recognized as one of the most ingenious forgers of the 20th century, can be used as an example [5,6]. Just with fakes based on Vermeer, the forger amassed a fortune worth more than half a billion dollars in today's currency. His work might have been still attributed to others if not for a cruel twist where he admitted to the forgeries in order to avoid being accused of collaborating with Nazis. History has delivers several other profiles of ingenious forgers, with the most recent one named Wolfgang Beltracchi [7]. This German painter confessed to forging hundreds of paintings in an international art scam netting millions of euros. In 2011, he was sentenced to six years in prison and, just overnight, became the celebrity called by the media "a forger of the century" $[7,8]$.

There are two common approaches to the authenticity evaluations of paintings. The long-established, traditional one is based on the opinion of an art expert or an art historian. 
It is rather subjective by nature, and as such, it sometimes does not comply with the demands of a modern forgery detection procedure. However, the beginning of the 20th century witnessed many spectacular scientific and technological developments, a wide range of which turned out to be useful for forgery detection. In the 1930s, for instance, basic analytical investigations, including X-ray [9] and UV photography [10], as well as a chemical analysis of the pigments [10], were introduced to fine art authentication. Their application in the analysis of the painting materials (pigments, dyes, binding media and support) has aided experts in confirmation of the authenticity of analyzed pieces of art and verification of the consistency of the materials used in the objects in question while keeping in mind the supposed time of its creations or authorship. Since the scientific approach is more objective than the traditional one, including comprehensive physicochemical examinations into the evaluations of paintings has become a necessity in the last decades.

Art experts, scientists or other experts involved in authenticity trials often find that terms like "highly probable", "suggested" and "possible" widely used in the scientific literature are not satisfactory for the court. In most cases, the expert is under pressure to answer the question about authenticity in the simplest "yes" or "no" terms. Sometimes, the court will accept evaluations delivered in percentages; for example: "the object is $80 \%$ authentic". Situations where it is possible to deliver a "yes" or "no" answer are the easiest, but how to quantify authenticity in numbers when the final opinion is indecisive? The combined data gathered during the case study might be strongly suggestive, but still, an answer totally verifying the attribution of the objects is troublesome. In such cases, an objective procedure based on the results obtained from a comprehensive investigation might be advantageous.

In this paper, we examine whether the decision process involved in authenticity evaluations may be supported by machine learning algorithms. The concept of decision support by a mathematical algorithm is not a new one. It has evolved from the theoretical studies of organizational decision making performed in the 1950s and 1960s [11]. Although the decision-making systems were intended to support the processes in management, in recent decades, they have become popular in other fields, such as healthcare or the service sector. For instance, many clinical decision support systems are already used by practitioners in diagnostics, drug dosing and drug prescribing [12]. Scoring systems are also being deployed to help banks in decisions of whether to grant credit [13].

Due to the vast amount of data collected in almost every area of our lives, data-driven decisions or predictions are becoming more and more popular. The term "machine learning" was coined in 1959 by A. L. Samuel [14] and is understood as giving computers the ability to learn without being explicitly programmed.

Machine learning algorithms can learn from and make predictions about data. One of the typical tasks tackled by them is classification. Provided the existing inputs may be divided into two or more classes, a classification algorithm produces a model that assigns unseen input to one or more of those classes [15]. An example of such a classification task would be assigning a given email to "spam" or "not spam" categories based on its contents [16]. However, applications are not limited to the IT area. A diagnosis could be, for instance, assigned to a patient when described by some observed characteristics [12] A customer's history may indicate whether he or she is inclined to buy a product or not $[17,18]$. Some patterns discovered in the data may indicate fraudulent attempts in many fields (e.g., telecommunications and taxes) $[17,18]$. Assuming that data on already conducted authenticity analyses of paintings is available together with their outcomes, from the conceptional point of view, the decision on the authenticity of a new piece of art is nothing but a classification task. Thus, at least theoretically, one could think of a system summarizing all existing data on that painting and suggesting a category it belongs to (e.g., "authentic" or "not authentic") on the basis of a comparison between the known cases and the one of interest.

Machine learning relies on computational statistics and mathematical optimization. As such, it often requires some mathematical background to interpret its results. Consequently, 
some reluctance against them may be observed among nonexperts. However, there is one concept called the "decision tree", which has a tremendous potential as a decision supporting tool [19], mainly due to its comprehensibility. Decision trees are simple to understand and to interpret, even by people with no prior expert knowledge. They may be visualized with graph-like structures easily translated into a set of readable rules of the form "if condition 1 and condition 2 and condition 3 are met, then".

Once the representation is generated, one does not even need a computer to apply it. That is the reason why we decided to use decision trees for our purposes and check their applicability in art forgery detection. The main goal of this paper is therefore to assess if machine learning algorithms may indeed be used as a kind of support for art experts.

We would like to combine decision trees with the attribution markers of paintings. The latter may be seen as outcomes of different analytical methods, both scientific and based on opinions, applied to the paintings under investigation. They have been identified in an in-depth analysis of over 50 case studies (Supplementary Materials Table S1) as factors that strongly influence the decision process in forgery detection. Every painting may be characterized by a vector of the markers that summarize the most important information regarding that piece of art. Those vectors will then be used as inputs for the decision tree model we decided to use in this work.

\section{Materials and Methods}

\subsection{Statement of Authenticity}

Authentication of a piece of art even nowadays is often based solely on the opinion of an art expert or an art historian. However, based on market demand and the currently available tools, a real statement of authenticity should include at least three levels of analysis (Figure 1): confirmation of provenance (i.e., authenticity of documents supporting ownership), verification of the artistic style of work by an art expert and scientific analysis of the object using generally approved methods, both invasive and noninvasive. The proposed authentication scheme matches the forensic analysis of various documents that is already well-established [20-22]. An in-depth analysis of the documentation associated with the art in question can assist in formulation of the final assessment. Scientific examination of the piece of art in question incorporates investigations of painting materials like pigments and media, canvas, wooden support, nails, etc. Discovery of the materials inconsistent with the supposed time of creation would suggest that the analyzed object is not authentic. On the other hand, the consistency of all the materials employed in the investigated piece of art with the time of creation does not necessarily prove the attribution of that object. In such a situation, further analysis might be required.

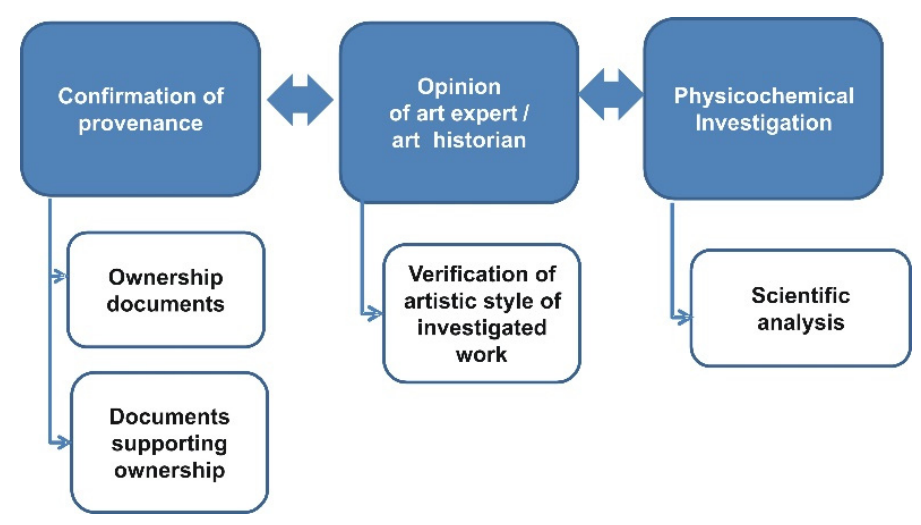

Figure 1. Three levels of the modern authentication procedure. The proposed scheme matches the forensic analysis of various documents that is already well-established.

The scientific analysis (i.e., the last step in Figure 1) consists of a wide range of various noninvasive and invasive analytical methods. In our opinion, the authentication process 
can benefit from purpose-oriented organization and implementation of these methods. A scheme presented in Figure 2 summarizes the proposed general approach applied in such tasks. The individual steps refer to the types of investigations and to the particular materials that should the analyzed but not directly to specific analytical techniques. The proposed scheme should also cover the procedures of collecting, storing and protecting samples, as well as general analysis methods. Moreover, the scheme should be repeatable and applicable to various objects. It includes various possibilities that should be considered during investigations. However, new investigative paths can be suggested with the growing amount of studies.

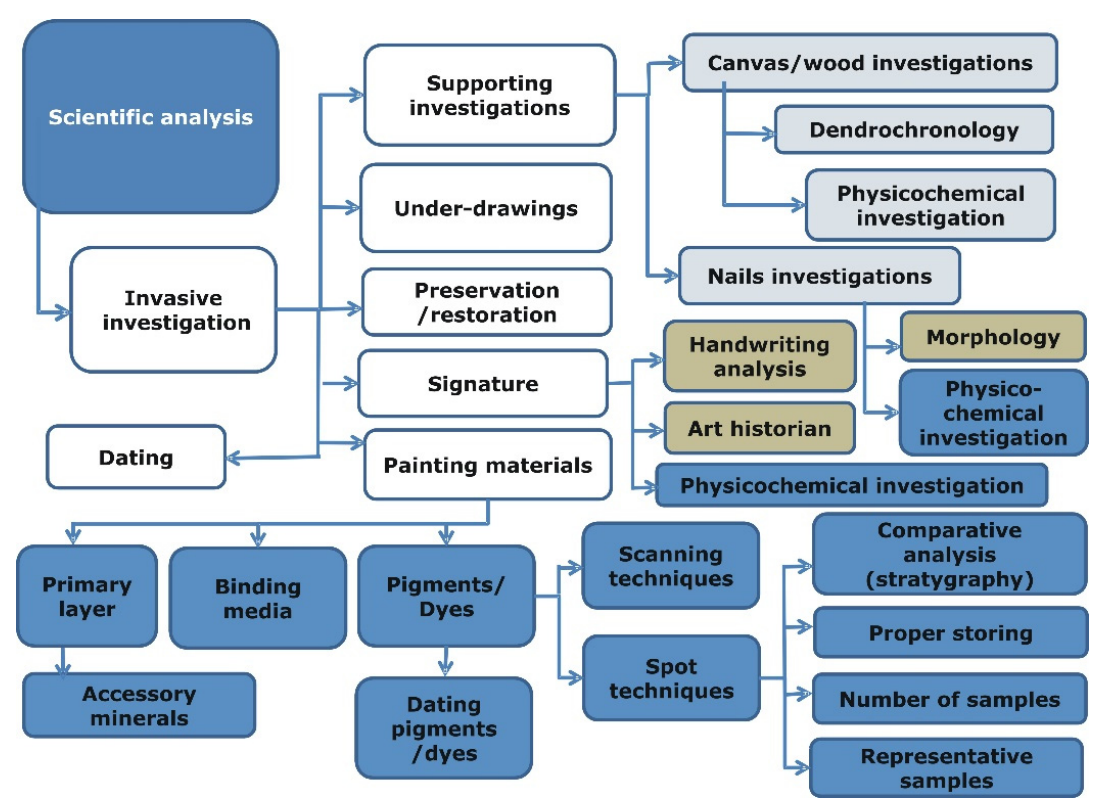

Figure 2. Analytical procedures supporting the authenticity examination process. Components of the scientific analysis (the last step of the procedure shown in Figure 1). The individual elements of the diagram correspond to different types of investigations.

\subsection{Case Studies}

The analytical procedure outlined in Figure 2 has been applied in more than 50 case studies (Table S1). The investigated collection of paintings originated from the 15th to 20th centuries. Some of the them were already positively attributed to J. M. Willmann [23-27], J. J. Kniechtl [28,29], A. Grottger [30], G. Penni (an apprentice of Raphael) [31], El Greco [32,33] or to the workshop of $\mathrm{H}$. Bosch [34]. In addition to the collection of paintings, the reported study included a unique set of historical maps [35]. The studies were conducted by the Cultural Heritage Research Laboratory at the University of Wrocław and the Laboratory of Analysis and Non-Destructive Investigation of Heritage Objects (LANBOZ) in Krakow [36-38]. All of the analyzed objects were subjected to combined spectroscopic analyses that included noninvasive investigations (Vis photography, UV fluorescence, IR photography and reflectography, $X$-ray photography and false color analysis,); X-ray fluorescence (XRF); macro-X-ray fluorescence (MAXRF); optical coherent tomography (OCT); optical microscopy of cross-sections (MO); scanning electron microscopy with energy dispersive spectroscopy (SEM-EDS); FTIR spectroscopy; micro-attenuated total reflection (ATR) techniques; micro-Raman spectroscopy and gas chromatography with mass spectrometry (GC-MS) [39].

The proposed 3-step authentication model (see Figure 1) has been applied, for example, to old-printed maps and a painting by J. J. Knechtl. As far as the maps are concerned, their prices offered on the antiquarian market are substantially higher when the objects on sale are colored rather than black and white. Marketability "enhancement" achieved by the addition of colors to maps printed between the 16th and 18th centuries is one of the most 
commonly seen fraudulent alterations. Step one of the proposed process was satisfied by the fact that the authenticity of the investigated maps was not questioned; they were printed, on paper, between the 16th and 18th centuries. The question was if the genuine maps were black and white or whether they were indeed printed in color. The documentation associated with the maps was authentic; nevertheless, the art experts could not confidently assess the authenticity of the objects, which led to step three, physicochemical studies to provide a more in-depth evaluation. As can be seen in Figure 3 (left panel), several noninvasive techniques were applied to assess if the maps were originally printed in color or if the color was added to enhance their market value: XRF, micro-Raman, fiber optic mid-FTIR and near-FTIR, UV/Vis fluorescence and UV/Vis absorbance [35].
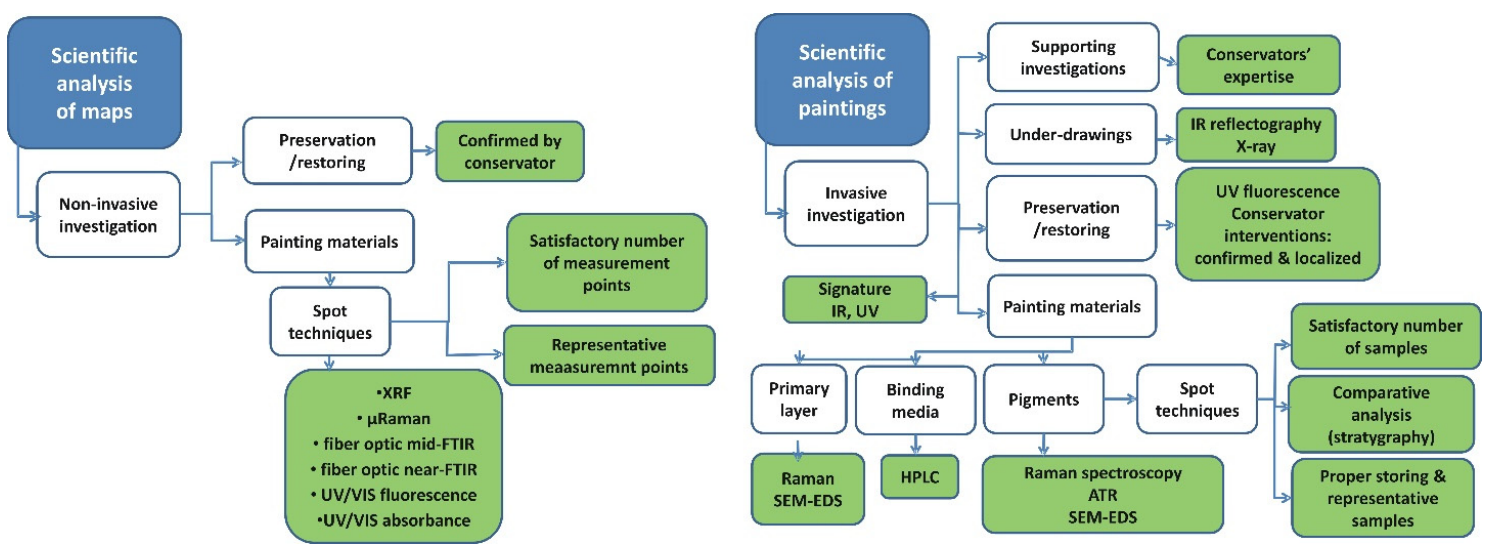

Figure 3. The proposed authentication model applied to different cultural heritage objects: maps printed between the 16th and 18th centuries (left panel) and the "Bolko Świdnicki" painting by J.J. Knechtl (right panel). Specific analytic techniques are now assigned to different types of investigations (see Figure 2 for the definitions of the latter ones).

In the second case study (Figure 3, right diagram), the proposed 3-step authentication process was applied to one of the paintings that were recently discovered in a private collection in Poland. The set was attributed to Joseph Jeremias Knechtl, one of the most famous painters of the 18th century in Silesia (Poland) who was nearly completely forgotten in the following centuries. While additional documentation associated with the painting was not available, the art historian was fairly confident that all but one of the discovered paintings were indeed authored by J.J. Knechtl. Since the first two steps of the process could not confirm the attribution of the painting called "Bolko II Świdnicki", a comprehensive comparative study implementing microscopic and spectroscopic analytical techniques was performed in order to authenticate. For the study, the art historian selected paintings representing all periods of Knechtl's creativity. They were subjected to noninvasive analyses like X-ray; IR reflectography; UV fluorescence and complementary examinations using micro-Raman spectroscopy, micro-ART spectroscopy, HPLC (high-pressure liquid chromatography), optical microscopy and SEM-EDS examinations. The information obtained for the representative set selected by the art historian allowed the creation of a "database" of painting materials used by Knechtl. The database was then used as a validation tool for investigation of the painting whose authenticity was questioned.

\subsection{Attribution Markers}

An in-depth analysis of over 50 case studies (Figure 4, for some examples) devoted to attribution and authenticity investigations of paintings allowed us to identify several markers [40] that strongly influenced the decision process. They are listed in Table 1. The application of attribution markers in authenticity assessments is fairly new, and many of the markers need detailed explanations, since their meanings are not well-established yet. For example, a marker called "verification of the artistic style" means that an art historian performed a robust analysis of the artistic style of the painting in question. "Historical 
pigments" indicates that pigments and dyes identified in the analyzed piece of art were consistent with the supposed time of creation of the investigated object. "Stratigraphy" implies that the stratigraphy of the sample collected from the analyzed painting was compared to the samples originating from a painting of known provenance and attribution. "Distinctive value", also referred to a "fingerprint" of the painter, refers to the unique feature of the painting technique or the specific material used by the painter. The marker "accessory minerals" attests to the origin of the raw materials used in the ground layer [29]. One of the markers listed in Table 1 and called "state consistent" is highly unique, since it is not determined by any analytical technique. It indicates the overall consistency of all available data, like materials, technique, preservation, etc., with the known facts about the expected creator. For example, the gathered data have not delivered any information contradicting the authenticity, but the craquelure does not look like the original or the varnish seems to be quite fresh, regardless of exhibiting the expected type of fluorescence. A similar factor is used in the assisted diagnostics [41].

Table 1. List of proposed attribution markers. Every marker summarizes a series of measurements conducted on a given painting.

\begin{tabular}{|c|c|}
\hline Marker & Marker Description \\
\hline Confirmed Authorship & $\begin{array}{c}\text { Ownership (or property rights) documents are in accordance with } \\
\text { the law and verified by a lawyer }\end{array}$ \\
\hline Unconfirmed Authorship & $\begin{array}{c}\text { Ownership (or property rights) documents not verified by a } \\
\text { lawyer }\end{array}$ \\
\hline Supporting Documents & $\begin{array}{l}\begin{array}{c}\text { Documents supporting ownership or authorship (e.g., letters and } \\
\text { photographs) }\end{array}\end{array}$ \\
\hline Test of Authenticity & $\begin{array}{l}\text { Ownership, property rights and/or supporting documents } \\
\text { verified by forensic investigations }\end{array}$ \\
\hline Verification of Artistic Style & Art historian analysis confirming the style \\
\hline Historical Support & $\begin{array}{l}\text { Support consistent with the supposed time of the } \\
\text { creation }\end{array}$ \\
\hline Support Consistency & Support consistent with the painter techniques \\
\hline Support Phys_Chem & Physicochemical examination of the support \\
\hline Support Dendrochronology & Dendrochronological examination of the support \\
\hline Transfer & Transfer (replacement) of the support \\
\hline Nails Morphology & Historical analysis of nails' morphology \\
\hline Nails Composition & Physicochemical analysis of nails \\
\hline UV & UV photography/UV luminescence \\
\hline IR & IR photography/IR reflectography \\
\hline RTG & X-ray photography/X-ray imaging \\
\hline Underdrawings Typical & $\begin{array}{l}\text { Underdrawings (or lack of them) consistent with the } \\
\text { painter techniques }\end{array}$ \\
\hline Historical Pigments & $\begin{array}{l}\text { Pigments and dyes consistent with supposed time of } \\
\text { creation }\end{array}$ \\
\hline Pigments Characteristic & Pigments and dyes characteristic for the painter techniques \\
\hline Distinctive Value & $\begin{array}{l}\text { The characteristic feature of the painting techniques-the presence } \\
\text { of the color underpainting }\end{array}$ \\
\hline Dating Pigment & $\begin{array}{l}\text { Dating pigment (i.e., pigment characteristic for the } \\
\text { supposed time of creation) }\end{array}$ \\
\hline Historical Binding & $\begin{array}{l}\text { Binding media consistent with the supposed time of } \\
\text { creation }\end{array}$ \\
\hline Typical Ground & Ground layer typical for the painter techniques \\
\hline Accessory Minerals & $\begin{array}{l}\text { Physicochemical investigation of the primary layer } \\
\text { and trace element analysis }\end{array}$ \\
\hline Original Varnish & Presence of original varnish \\
\hline Stratigraphy & Stratigraphy typical for painter's techniques \\
\hline Representative Sample & Samples representative for the object \\
\hline
\end{tabular}


Table 1. Cont.

\begin{tabular}{cc}
\hline Marker & Marker Description \\
\hline $\begin{array}{c}\text { Number of Samples/Number of } \\
\text { Measurements Points }\end{array}$ & Sufficient number of samples/Number of Measurement Points \\
\hline Conservator's Interventions & Presence of conservator's interventions \\
\hline Signature & Signature attributed to the author \\
\hline Signature Graphology & Handwriting investigations of the signature \\
\hline Signature Phys_Chem & Physicochemical investigations of the signature \\
\hline State Consistent & Declared state of the preservation consistent with the \\
investigation results
\end{tabular}

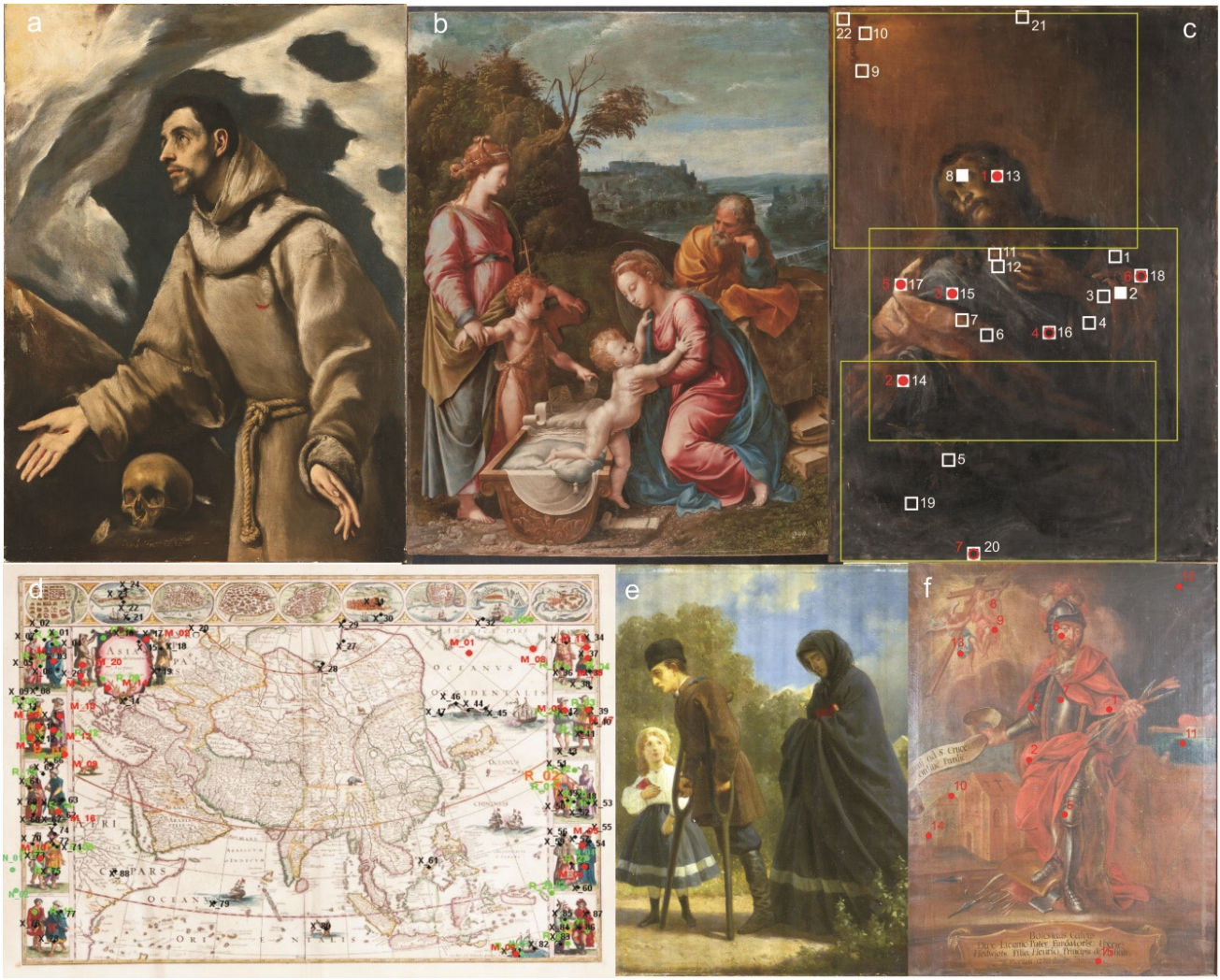

Figure 4. Example of investigated pieces of art: (a) El Greco "Ecstasy of Saint Francis" ca 1575-1580, the Diocese Museum in Siedlce (Poland). (b) G. Penni "The Holy Family with Saint John and Saint Catherine", National Museum in Warsaw (Poland). (c) M.L. Willmann "Christ in Gethsemane", Church of the Assumption of the Blessed Virgin Mary in Żagan (Poland). (d) Willem \& Joan Blaeu, Theatrum orbis terrarum sive Atlas Novus, Amsterdam 1649-1655, Ossoliński National Institute in Wrocław (Poland). (e) A. Grotter "After the uprising" 1864, National Museum in Wrocław (Poland), (f) J.J Knechtl “Bolko II Świdnicki” ca. 1720, Krzeszów (Poland).

\subsection{Analyzed Dataset}

The data obtained during the scientific investigation of 55 paintings were used as a training set to confirm the applicability of the data mining process guided by decision trees for art classification. All the paintings were characterized by a series of measurements corresponding to the markers (Table 1) appropriate for each specific case study. The values of the markers are shown in Tables 2 and 3. Each column in these tables represents a single painting and delineates the scientific data (markers) available for the investigated painting. The numbers 1 and -1 , represent measurements with positive and doubtful/negative outcomes, respectively. An empty cell means that a factor was not investigated for the given painting. 
Table 2. Our dataset consists of 55 paintings, each of which is characterized by a subset of attribution markers. An empty cell indicates that the corresponding marker was not investigated. Value "1" of a marker means that the corresponding examination was positive. Measurements with negative outcomes are represented by the value " -1 ".

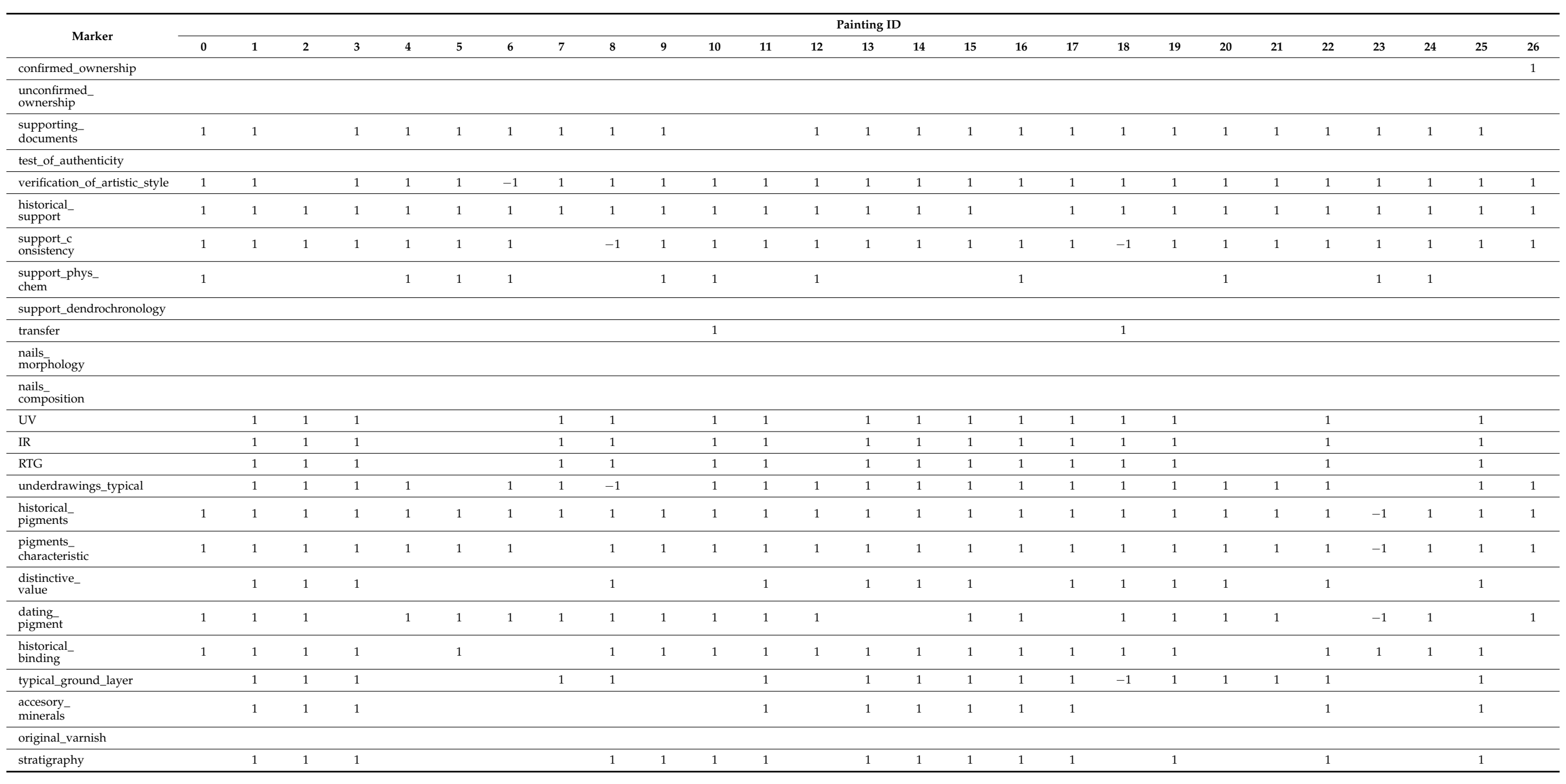


Table 2. Cont.

\begin{tabular}{|c|c|c|c|c|c|c|c|c|c|c|c|c|c|c|c|c|c|c|c|c|c|c|c|c|c|c|c|}
\hline \multirow{2}{*}{ Marker } & \multicolumn{27}{|c|}{ Painting ID } \\
\hline & 0 & 1 & 2 & 3 & 4 & 5 & 6 & 7 & 8 & 9 & 10 & 11 & 12 & 13 & 14 & 15 & 16 & 17 & 18 & 19 & 20 & 21 & 22 & 23 & 24 & 25 & 26 \\
\hline $\begin{array}{l}\text { representative } \\
\text { sample }\end{array}$ & 1 & 1 & 1 & 1 & 1 & 1 & 1 & 1 & 1 & 1 & 1 & 1 & 1 & 1 & 1 & 1 & 1 & 1 & 1 & 1 & 1 & 1 & 1 & 1 & 1 & 1 & 1 \\
\hline $\begin{array}{l}\begin{array}{l}\text { number_of } \\
\text { samples }\end{array} \\
\end{array}$ & 1 & 1 & 1 & 1 & 1 & 1 & 1 & 1 & 1 & 1 & 1 & 1 & 1 & 1 & 1 & 1 & 1 & 1 & 1 & 1 & 1 & 1 & 1 & 1 & 1 & 1 & 1 \\
\hline $\begin{array}{l}\text { conservator } \\
\text { interventions }\end{array}$ & 1 & 1 & 1 & 1 & 1 & & 1 & 1 & 1 & & 1 & 1 & 1 & 1 & 1 & 1 & 1 & 1 & 1 & 1 & 1 & 1 & 1 & & & 1 & \\
\hline signature & & & 1 & & 1 & & & 1 & & 1 & & 1 & 1 & & & & & & & & 1 & 1 & & & & & \\
\hline $\begin{array}{l}\text { signature_ } \\
\text { graphology }\end{array}$ & & & & & & & & & & & & & 1 & & & & & & & & & & & & & & \\
\hline state_consistent & 1 & 1 & 1 & 1 & 1 & 1 & 1 & 1 & 1 & 1 & 1 & 1 & 1 & 1 & 1 & 1 & 1 & 1 & 1 & 1 & 1 & 1 & 1 & -1 & 1 & 1 & 1 \\
\hline is_original? & YES & YES & YES & YES & YES & YES & YES & YES & YES & YES & YES & YES & YES & YES & YES & YES & YES & YES & YES & YES & YES & YES & YES & YES & YES & YES & YES \\
\hline
\end{tabular}

Table 3. Our dataset (continued). See the caption of Table 2 for more details

\begin{tabular}{|c|c|c|c|c|c|c|c|c|c|c|c|c|c|c|c|c|c|c|c|c|c|c|c|c|c|c|c|}
\hline \multirow{2}{*}{ Marker } & \multicolumn{27}{|c|}{ Painting ID } \\
\hline & 28 & 29 & 30 & 31 & 32 & 33 & 34 & 35 & 36 & 37 & 38 & 39 & 40 & 41 & 42 & 43 & 44 & 45 & 46 & 47 & 48 & 49 & 50 & 51 & 52 & 53 & 54 \\
\hline confirmed_ownership & 1 & 1 & & & & & & & & & & & 1 & & & & & & & & & & & & & & \\
\hline \multicolumn{28}{|l|}{$\begin{array}{l}\text { unconfirmed_ } \\
\text { ownership }\end{array}$} \\
\hline $\begin{array}{l}\text { supporting- } \\
\text { documents }\end{array}$ & & & 1 & & 1 & & & & 1 & & & & & & & & & & & & & & & 1 & 1 & 1 & \\
\hline \multicolumn{28}{|l|}{ test_of_authenticity } \\
\hline verification_of_artistic_style & 1 & . & 1 & 1 & 1 & & -1 & 1 & 1 & & & 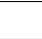 & 1 & 1 & 1 & 1 & 1 & 1 & 1 & 1 & 1 & 1 & 1 & 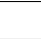 & 1 & . & 1 \\
\hline $\begin{array}{l}\text { historical_- } \\
\text { support }\end{array}$ & 1 & 1 & 1 & 1 & 1 & 1 & 1 & 1 & 1 & 1 & & 1 & 1 & 1 & 1 & 1 & 1 & 1 & 1 & & & & & 1 & 1 & 1 & 1 \\
\hline $\begin{array}{l}\text { support_c } \\
\text { onsistency }\end{array}$ & 1 & 1 & 1 & 1 & 1 & & & 1 & 1 & 1 & 1 & 1 & 1 & 1 & -1 & 1 & 1 & 1 & & & & & & 1 & 1 & 1 & \\
\hline $\begin{array}{l}\text { support_phys_ } \\
\text { chem }\end{array}$ & & 1 & & & & & & & 1 & & & & & & -1 & 1 & & & 1 & & & & & & & & \\
\hline \multicolumn{28}{|l|}{ support_dendrochronology } \\
\hline transfer & & & & & & & & & 1 & & & & & & & & & & & & & & & & & & \\
\hline $\begin{array}{l}\text { nails } \\
\text { morphology }\end{array}$ & & & & & & & & & & & & & & -1 & & & & & & & & & & & & & \\
\hline \multicolumn{28}{|l|}{$\begin{array}{l}\begin{array}{l}\text { nails_- } \\
\text { composition }\end{array} \\
\end{array}$} \\
\hline UV & 1 & & 1 & 1 & 1 & & & 1 & 1 & 1 & 1 & 1 & 1 & 1 & 1 & 1 & 1 & 1 & 1 & 1 & 1 & 1 & 1 & 1 & 1 & 1 & 1 \\
\hline IR & 1 & & 1 & 1 & 1 & & & 1 & 1 & 1 & 1 & 1 & 1 & 1 & 1 & 1 & 1 & 1 & 1 & 1 & 1 & 1 & 1 & 1 & 1 & 1 & 1 \\
\hline
\end{tabular}


Table 3. Cont.

\begin{tabular}{|c|c|c|c|c|c|c|c|c|c|c|c|c|c|c|c|c|c|c|c|c|c|c|c|c|c|c|c|}
\hline \multirow{2}{*}{ Marker } & \multicolumn{27}{|c|}{ Painting ID } \\
\hline & 28 & 29 & 30 & 31 & 32 & 33 & 34 & 35 & 36 & 37 & 38 & 39 & 40 & 41 & 42 & 43 & 44 & 45 & 46 & 47 & 48 & 49 & 50 & 51 & 52 & 53 & 54 \\
\hline RTG & 1 & & 1 & 1 & 1 & & & 1 & 1 & 1 & 1 & 1 & 1 & 1 & 1 & 1 & 1 & 1 & 1 & 1 & 1 & 1 & 1 & 1 & 1 & 1 & 1 \\
\hline underdrawings_typical & 1 & & 1 & 1 & 1 & & & & 1 & & & & 1 & & & 1 & 1 & 1 & 1 & 1 & 1 & 1 & 1 & 1 & 1 & & -1 \\
\hline $\begin{array}{l}\text { historical_- } \\
\text { pigments }\end{array}$ & 1 & 1 & 1 & 1 & 1 & -1 & -1 & 1 & -1 & 1 & -1 & -1 & 1 & 1 & 1 & 1 & 1 & 1 & 1 & 1 & 1 & 1 & 1 & 1 & 1 & 1 & 1 \\
\hline $\begin{array}{l}\text { pigments } \\
\text { characteristic }\end{array}$ & 1 & 1 & 1 & 1 & 1 & -1 & -1 & 1 & -1 & -1 & -1 & -1 & 1 & & & 1 & 1 & 1 & 1 & 1 & 1 & 1 & 1 & 1 & 1 & & \\
\hline $\begin{array}{l}\text { distinctive } \\
\text { value }\end{array}$ & 1 & & 1 & 1 & 1 & & & -1 & -1 & & & & & & & & 1 & 1 & 1 & 1 & 1 & 1 & 1 & & 1 & & \\
\hline $\begin{array}{l}\text { dating_- } \\
\text { pigment }\end{array}$ & 1 & 1 & 1 & 1 & & -1 & -1 & & -1 & -1 & -1 & -1 & 1 & & & 1 & 1 & 1 & & & & & & 1 & 1 & 1 & \\
\hline $\begin{array}{l}\text { historical_- } \\
\text { binding }\end{array}$ & & & 1 & 1 & 1 & & & & & & & & -1 & & 1 & 1 & 1 & 1 & & & & & & 1 & 1 & 1 & \\
\hline typical_ground_layer & 1 & & 1 & 1 & 1 & & & & 1 & 1 & & 1 & 1 & 1 & 1 & 1 & 1 & 1 & 1 & 1 & 1 & & 1 & 1 & 1 & & 1 \\
\hline $\begin{array}{l}\text { accesory_- } \\
\text { minerals }\end{array}$ & & & 1 & 1 & 1 & & & & & & & & & & & & & & & & & & & & 1 & & \\
\hline original_varnish & & & & & & & & & & & & & & & & 1 & & & & & & & & & & 1 & \\
\hline stratigraphy & 1 & & 1 & 1 & 1 & & & & & & & & & & & 1 & & & & & & 1 & & 1 & 1 & & \\
\hline $\begin{array}{l}\text { representative } \\
\text { sample }\end{array}$ & 1 & 1 & 1 & 1 & 1 & & 1 & 1 & 1 & 1 & 1 & 1 & & & & 1 & 1 & 1 & 1 & 1 & 1 & 1 & 1 & 1 & 1 & 1 & \\
\hline $\begin{array}{l}\text { number_of_ } \\
\text { samples }\end{array}$ & 1 & 1 & 1 & 1 & 1 & & 1 & 1 & 1 & 1 & 1 & 1 & & & & 1 & 1 & 1 & 1 & 1 & 1 & 1 & 1 & 1 & 1 & 1 & \\
\hline signature & & 1 & 1 & & & 1 & 1 & 1 & & 1 & 1 & 1 & & & & 1 & & & 1 & 1 & 1 & 1 & & & & & \\
\hline \multicolumn{28}{|l|}{$\begin{array}{l}\text { signature_ } \\
\text { graphology }\end{array}$} \\
\hline $\begin{array}{l}\text { signature__ } \\
\text { phys_chem }\end{array}$ & & & & & & & & & & & & & & & & 1 & & & & & & & & & & & \\
\hline state_consistent & 1 & 1 & 1 & 1 & 1 & -1 & -1 & -1 & -1 & -1 & -1 & -1 & -1 & & & 1 & 1 & 1 & 1 & & 1 & 1 & 1 & 1 & 1 & 1 & -1 \\
\hline is_original? & YES & YES & YES & YES & YES & YES & NO & NO & NO & NO & NO & NO & NO & NO & NO & YES & YES & YES & YES & YES & YES & YES & YES & YES & YES & NO & NO \\
\hline
\end{tabular}




\subsection{Decision Trees}

Decision trees are a simple machine learning algorithm that illustrates how a target variable (authenticity assessment, in our case) is explained or predicted using a set of predictor attributes (i.e., attribution markers) [42]. As their name conveys, decision trees are tree-like diagrams composed of nodes. The topmost node, called the root, represents the whole dataset. It is split into child nodes by a selected attribute to produce subsets of data with smaller impurities than the original one. The procedure is then repeated until the nodes cannot be further partitioned (because they contain data samples of the same kind, e.g., authentic paintings only) or the maximum depth of the tree is reached. In the latter case, no perfect partitioning of the data has been reached.

Every internal node of the tree represents a test on a marker. Each branch is an outcome of the test (see Figures 5 and 6). The paths from the root to leaf nodes, i.e., the nodes with no children, serve as the classification rules.

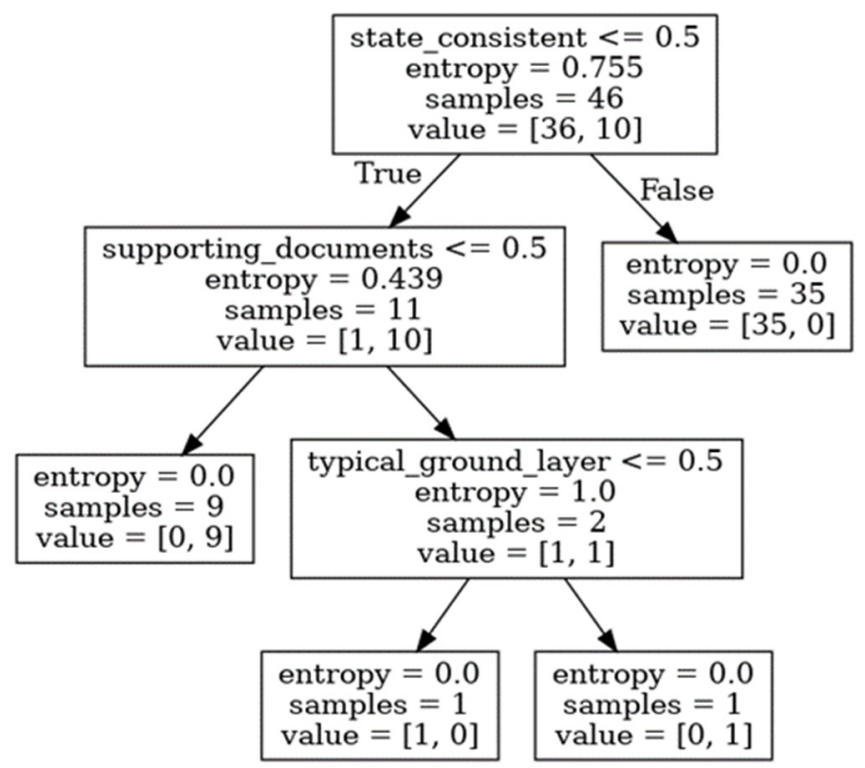

Figure 5. Decision trees built on the training data (i.e., paintings with IDs from 0 to 45 in Tables 2 and 3). The "state consistent" marker seems to be the most important one for splitting the data, since it allows dividing it into a pure sample of authentic paintings (right child) and a sample consisting of all but one of the forged paintings (left child). Two further splits were performed to separate the one authentic painting from the forged sample.

The biggest advantage of the decision trees is that they are very simple models. They require little statistical background, are easy to interpret and are very for in conveying information. As for the drawbacks, due to a tendency toward overfitting, they are usually not the best choice for a robust classifier. Having that said that, we will stick to decision trees for their interpretability.

When applied to attribution markers, the decision tree method should assist in: (a) determining which markers are necessary, (b) establishing their relative relevance and (c) predicting whether a painting with known values of the attribute markers is authentic. The decision tree approach should also improve the reliability of partial authenticity assessments. 


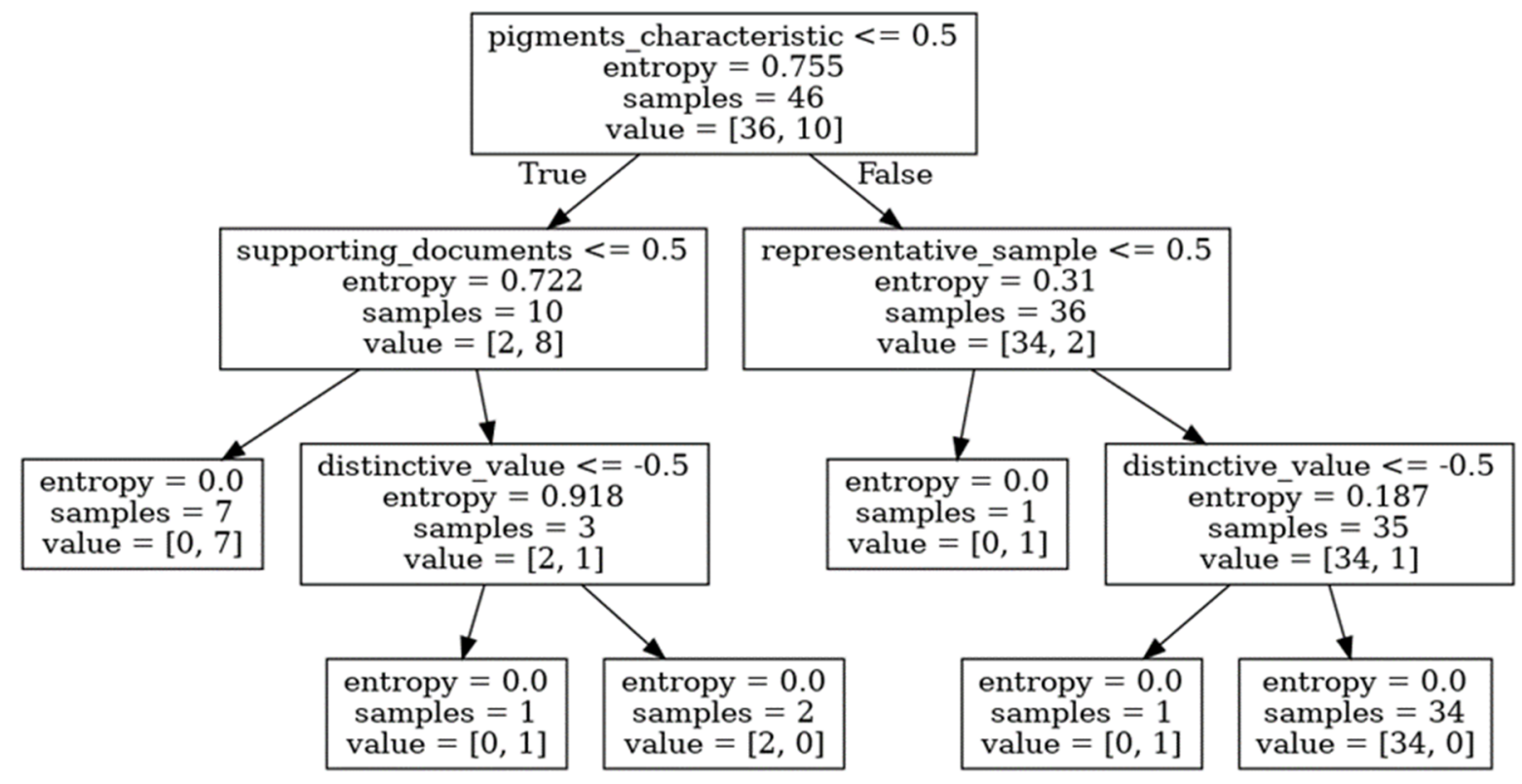

Figure 6. Decision tree built after the removal of the "state consistent" marker from the dataset. The "pigments characteristic" feature has become the most important one.

\section{Results and Discussion}

The open-source programming language Python [43], together with the Pandas and Scikit-learn [44] modules, were used to analyze the data and to build the decision tree model.

\subsection{Dataset Characteristics}

Our dataset consisted of 55 paintings, 43 of which were assessed as authentic (see Tables 2 and 3 for details). The investigations performed for each item are shown in Figure 7 (to recall, each investigation corresponds to one attribution marker). The paintings differed from each other in the number and type of tests conducted to check their authenticity. In other words, there was no standard set of attributes the examining laboratories checked during the authenticity assessment. In fact, as is shown in Figure 5 and Tables 2 and 3, the presented dataset did not include any sample with all 32 markers collected.

Usually, less than 20 tests are performed to classify a painting. The reason is at least twofold. First, many case studies are subjected to several limitations, including time and/or budget constraints, restricted access to a specialized equipment or lacking collaboration between experts from different domains. Moreover, the individual investigations are often conducted sequentially, one after the other. It may happen, in this case, that a subset of them is already conclusive, making the rest superfluous.

To elaborate more on that issue, let us have a look at how often every attribution marker was used. The results of the assessment are shown in Figure 8 and indicate that, indeed, there is no standard procedure for verifying authenticity. The usage frequencies for the analyzed markers were spread over a broad range of values. Additionally, five attribution markers ("unconfirmed ownership", "test of authenticity", "support dendrochronology", "nails composition" and "original varnish") were not used at all. It seems that they were considered not crucial, at least for the available dataset, and might probably be omitted in further considerations. In the literature, they are rather rarely listed in authenticity investigations [6]. 


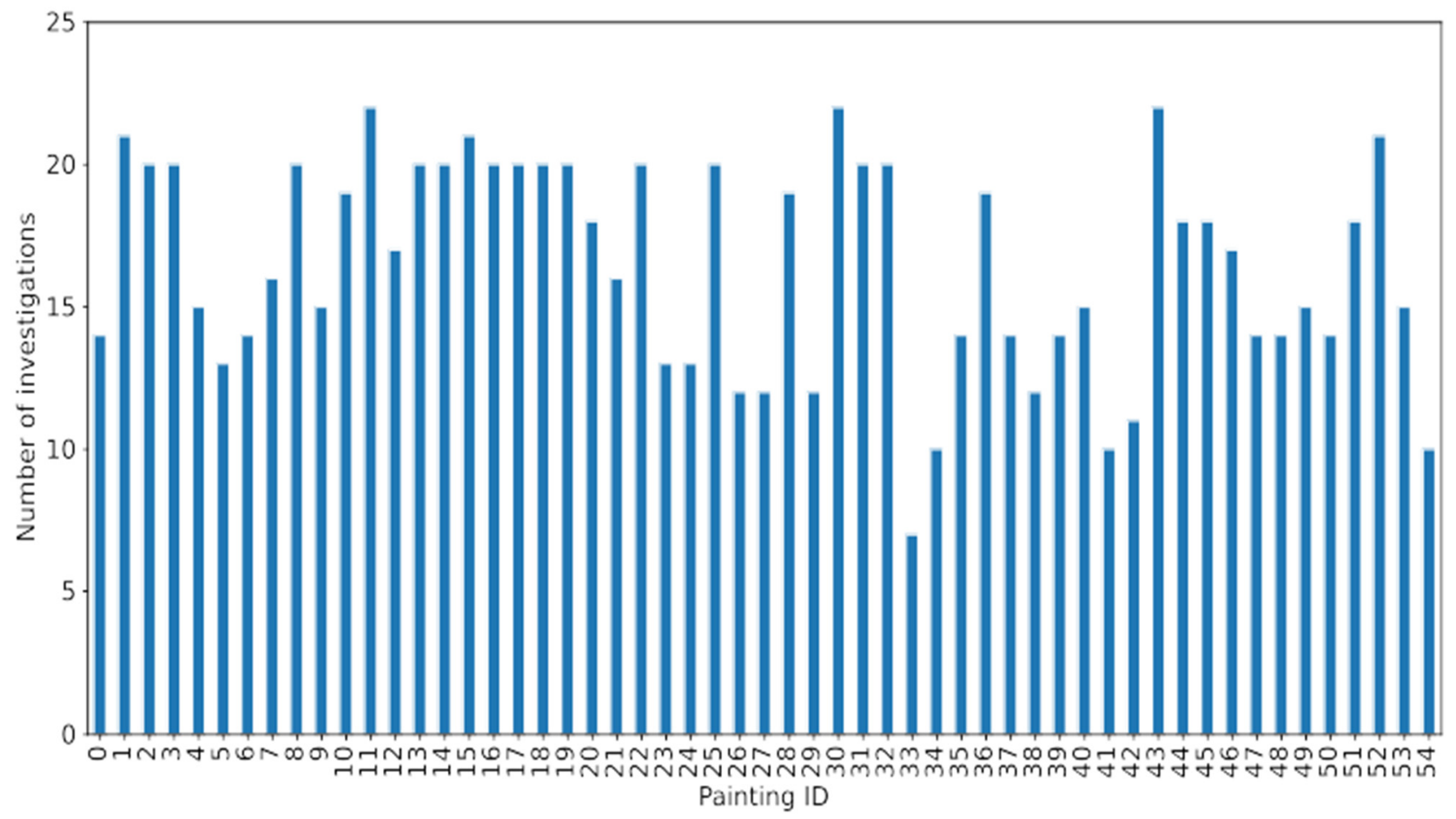

Figure 7. Number of investigations conducted for paintings in the dataset. The data does not contain any sample with all 32 markers collected. Usually, less than 20 tests were performed to characterize an item.

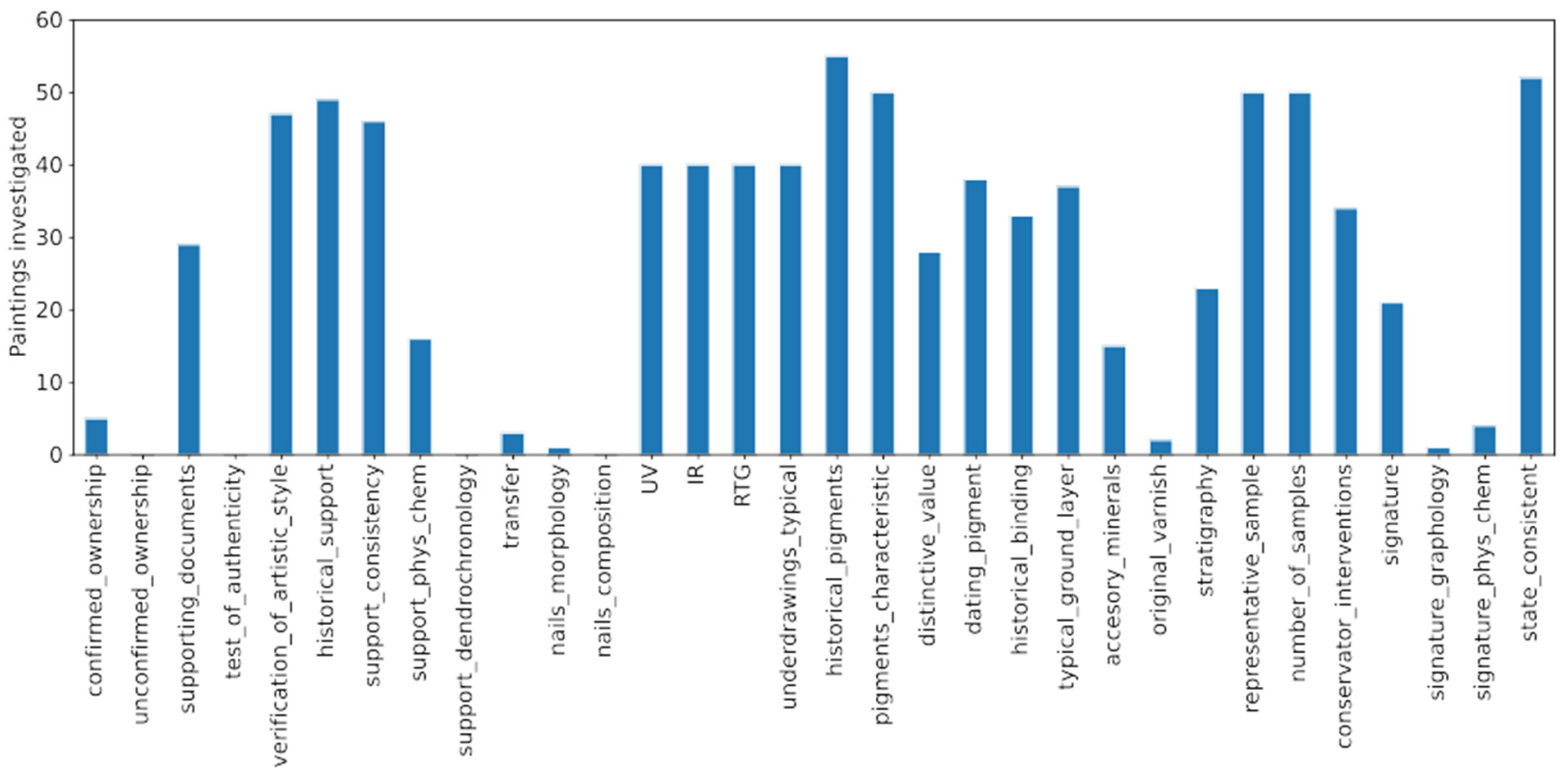

Figure 8. Frequencies of the usage of different attribution markers in the dataset. Five markers (unconfirmed ownership, test of authenticity, support dendrochronology, nails composition and original varnish) were not used at all and may probably be omitted in further authenticity investigations.

In Figure 9, the investigations with negative outcomes are shown. The analyzed dataset suggests some level of differentiation in the importance/contribution of given authenticity marker to the overall investigation. Three out of four markers with the highest negative outcome were associated with the pigment analysis ("dating_pigment", "pig- 
ments_characteristic" and "historical_pigments"). Such results underline the significance of the pigment analysis in the overall authentication process. In the case of the "dating_pigment" marker, any negligence in identifying all the places in which conservation work was performed can result in erroneous authenticity attribution. The highest number of negative outcomes was assigned to the "state _consistent" marker. In the next section, this marker is discussed in more detail. Nevertheless, the attribution markers shown in the figure are of great importance. Since one expects a painting with all positive examinations to be authentic, the forged category has to be related to negative values of the markers.

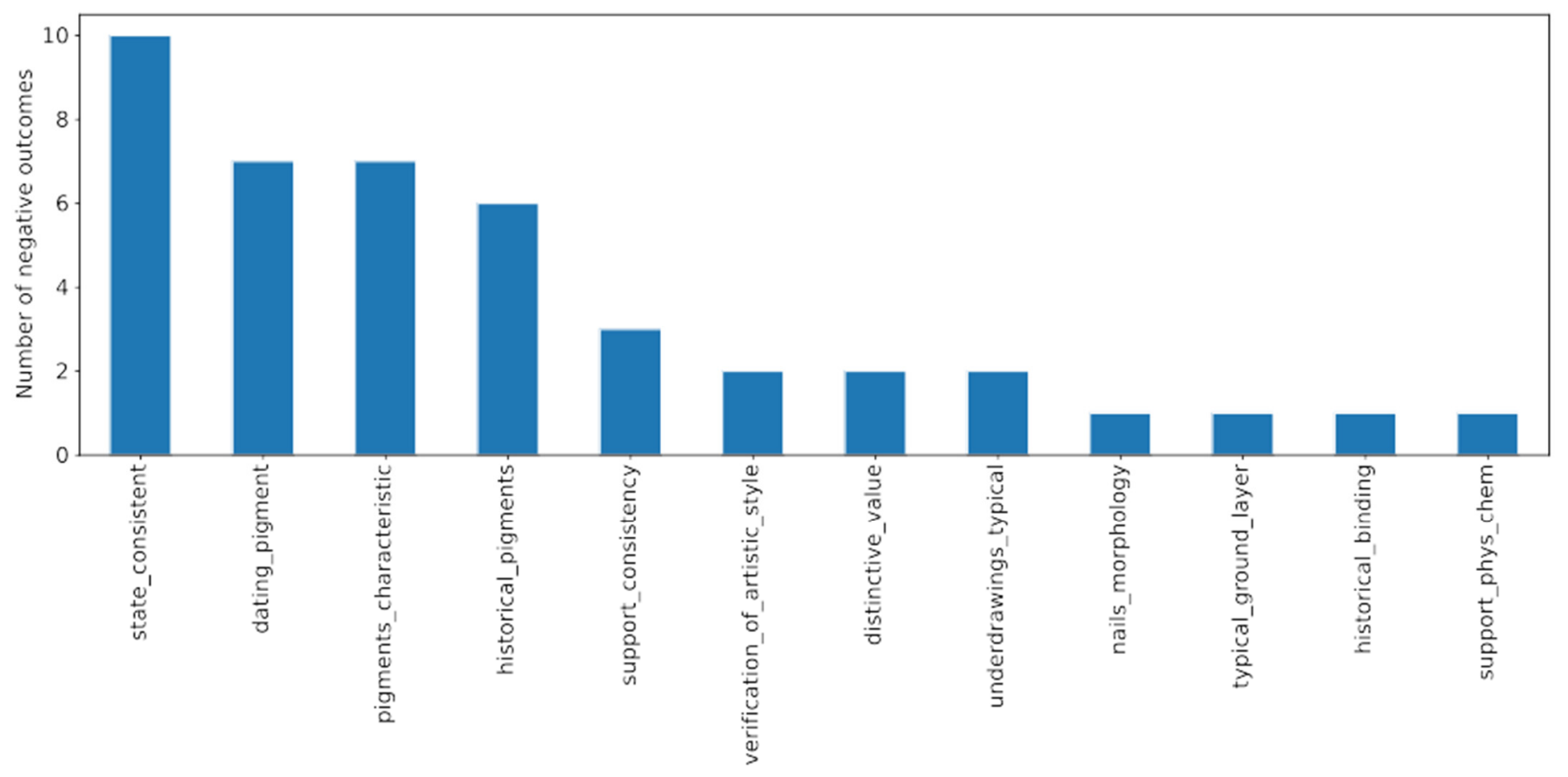

Figure 9. Investigations with negative outcomes. Since the forged paintings are expected to be characterized by at least one negative measurement, the features shown in this plot are of great importance for the examination process.

\subsection{Building the Decision Tree}

In our first attempt to build a decision tree, we split the data shown in Tables 2 and 3 into two subsets: the training one consisting of 46 paintings (with IDs from 0 to 45 ) used to train the model and the test one with the remaining nine paintings. The latter one was then used to assess the accuracy of the resulting classifiers. This partitioning of the data is in accordance with its collection chronology. At the beginning of the project, only the data for the first 46 paintings from Tables 2 and 3 were available. The remaining part was provided much later. Thus, it was a rather natural choice to use them for the test purposes. It should be stressed, however, that such a manual splitting of data is not the usual approach to machine learning. We will address that issue later in this section.

Our training set contained 36 authentic paintings and 10 forged ones (see Tables 2 and 3). The DecisionTreeClassifier object from the scikit-learn library [44] was used to train the model. We used trees with a maximum depth equal to four. Entropy [19] was used to measure the quality of the split at each node of the tree. A search of the parameter spaces of the model was performed in order to choose the above values.

The resulting decision tree is shown in Figure 5. We see that the splits determined by the algorithm are clearly outlined and easy to trace. As already mentioned, we started with 46 samples at the root node. The "state consistent" marker was used for the first split. The test on the marker at the root may indicate that we are dealing with continuous values, but it is only an artifact of the visual representation of the trees. In our case, the condition state consistent $\leq 0.5$ is satisfied if the value of the marker is simply -1 (i.e., a negative outcome 
of the corresponding investigation) or 0 (missing value, no corresponding investigation). The value of entropy at the root (0.755) indicated that the sample contained a mixture of authentic and forged items. The data was split into two child nodes with 11 (left) and 35 (right) samples. The left child corresponded to paintings satisfying the condition at the root node. Note that, after the split, the right child was already pure (entropy equal to 0 ) and contained authentic paintings only. Among the 11 paintings in the left node, one was authentic, and the rest were forged. To separate them from each other, two further splits on the left node were carried out.

First, the supporting documents marker was used to split the subset into two child nodes. Again, the left one corresponded to negative or missing values of the marker. The second split in the left node, based on the supporting documents, created two child subsets. The left child consisted of nine samples and was already pure. In other words, all the samples with both state consistent and supporting documents markers with values -1 and 0 were forged. The right child consisted of only two samples, one authentic and one not, which could be separated from each other by the application of yet another marker, the typical ground layer.

The decision tree applied in the reported case studies may be translated into the following set of rules shown in Algorithm 1:

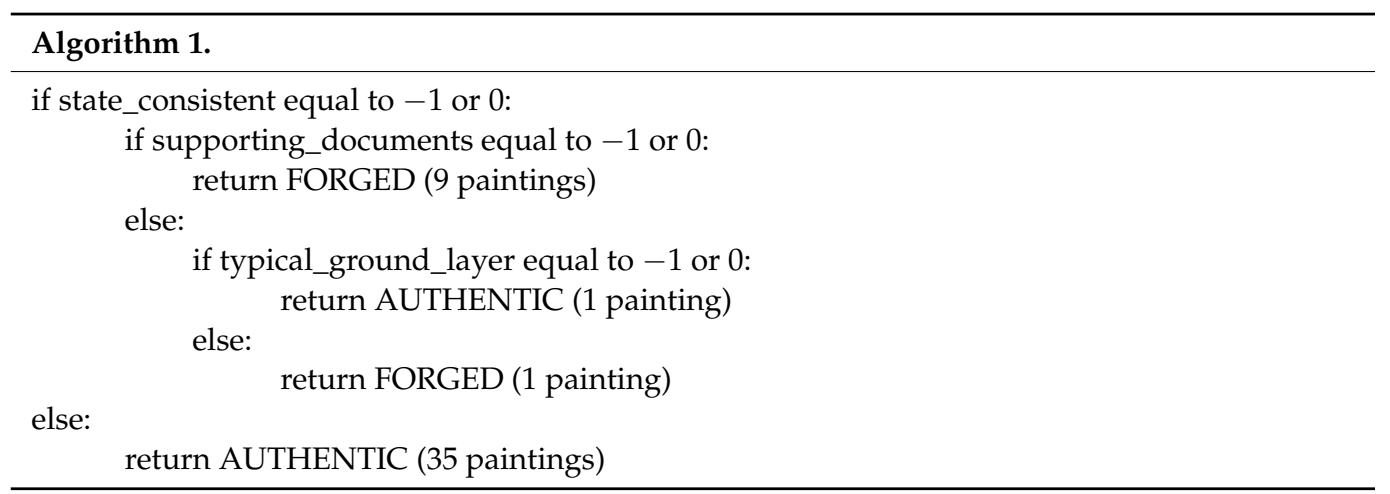

To conclude this section, we would like to stress that continuing the partitioning of data until all of the leaf nodes contain pure samples is fine if the major goal of the procedure is to summarize and convey the information contained in the data. However, it is not the best idea if one looks for a reasonable classifier, since, in this scenario, the model will probably overfit and have some problems with the generalization of unseen data. In this case, it would be probably better to stop after the first split.

\subsection{Relevance of the Attribution Markers}

The decision tree shown in Figure 5 suggests that the "state consistent" marker is the most important one in the authenticity attribution cases. It is not only optimal for the first split but also allows partitioning of the data into a pure subset of authentic paintings and an almost pure one with all but one of samples being forged. The other two attributes shown in the tree are used to extract the remaining authentic painting from the latter subset.

Surprisingly, based on the presented case study, it seems that only a small subset of the proposed attribution markers is required to assess the authenticity of the paintings. Among them, as it was already shown, the "state consistent" marker is of great importance. This attribute is often underestimated or even disregarded by experts involved in physicochemical investigations, because it does not describe any analytical results. Rather, it stands for an overall impression of an art expert. Interestingly, this rather subjective marker seems to be very important in an art historian's expertise.

A conservation scientist examining the authenticity of a painting relies on the results obtained via application of a broad range of well-established scientific techniques. While the results might not be $100 \%$ conclusive, the analysis does not rely on emotions and, hence, can be perceived as more objective than the opinion of an art expert. However, by definition, 
the "state consistent" marker is a subjective feeling- and experience-based assessment of art experts. This subjective impression that "something is not right" can, and often does, lead to additional scientific investigations that would have not been performed if the art expert was able to form a firm opinion.

The relevance of a marker in the decision tree may be estimated by the so-called feature importance. It is calculated as the (normalized) total reduction of the entropy brought about by that marker. If the reduction is very close to zero (referred to as vanishing importance), the corresponding marker is irrelevant and may be omitted in the analysis.

The attribution markers with nonvanishing importance are listed in Table 4. The values confirm our previous findings. The "state_consistent", "supporting_documents" and "typical_ground_layer" features present themselves as the most important factors. The remaining ones can be neglected.

Table 4. Relative importance of the features for the decision tree shown in Figure 5. Only the markers with nonvanishing importance are listed. The remaining ones can be neglected (they have no impact on the classification results).

\begin{tabular}{lc}
\hline \multicolumn{1}{c}{ Attribution Marker } & Importance \\
\hline State_consistent & 0.864 \\
Supporting_documents & 0.081 \\
Typical_ground_layer & 0.055 \\
\hline
\end{tabular}

\subsection{First Attempt to Classification}

Let us examine the efficiency of the decision tree model when it is applied as a classifier to new paintings. As it was mentioned before, the test set consisted of nine samples, seven of which had been assessed by experts as authentic. The attribution markers for those paintings are summarized in Table 3 (IDs from 46 to 55). The results of the classification are presented in Table 5. As we can see, the classifier made one mistake by predicting the "Authentic" class for one of the forged paintings. In other words, the accuracy of the classifier was equal to $88 \%$. In general, accuracies close to 90 percent are perceived as good.

Table 5. Accuracy of the classifier shown in Figure 5. The model was tested on the test data (paintings with IDs from 46 to 55 in Table 3). The predictions for the paintings are compared with their labels assessed by experts.

\begin{tabular}{ccc}
\hline Painting ID & Predicted Class & Real Class \\
\hline 1 & Authentic & Authentic \\
2 & Authentic & Authentic \\
3 & Authentic & Authentic \\
4 & Authentic & Authentic \\
5 & Authentic & Authentic \\
6 & Authentic & Authentic \\
7 & Authentic & Authentic \\
8 & Forged & Forged \\
9 & Authentic & Forged \\
\hline
\end{tabular}

\subsection{Decision Trees on Subsets of Features}

The decision trees can also be used to check the consequences of feature removal from the training set. For instance, assume that there is no "state consistent" marker in the data or that this subjective marker has been intentionally removed by an expert. The tree built for that case is shown in Figure 6. The new model requires more features to separate both classes. However, it is still possible to achieve full separation with a rather short tree. The marker called "pigments characteristic" becomes the most important one and allows for a division of the painting into two child nodes with 10 (two authentic and eight forged) and 36 (34 authentic and two forged) samples. The importance of all markers used in the tree 
are summarized in Table 6. Again, the revised model displays $88 \%$ accuracy in predicting a painting's authenticity when applied to the test data.

Table 6. Relative importance of the features for the decision tree shown in Figure 6. The tree was built after the "state consistent" marker was removed from the data. Only markers with nonvanishing importance are listed. The remaining ones can be neglected (they have no impact on the classification results).

\begin{tabular}{lc}
\hline \multicolumn{1}{c}{ Attribution Marker } & Importance \\
\hline Pigments_characteristic & 0.471 \\
Distinctive_value & 0.268 \\
Representative_sample & 0.132 \\
Supporting_documents & 0.128 \\
\hline
\end{tabular}

\subsection{Cross-Validation of the Classifier}

The overall accuracy of $88 \%$ is not bad, but until now, we worked with the same data split all of the time. Since the classification results can depend on a particular choice for the training and test subsets, we carried out a stratified k-fold cross-validation of the model. In this procedure, the data is split randomly into $\mathrm{k}$ smaller sets (called folds) in such a way that the percentage of samples for each class is preserved across the folds. Then, a decision tree is built using k-1 folds as the training data. The remaining fold is used for validation. The procedure is repeated for different partitionings of the folds into the training and test subsets. The final performance is simply an average of the values computed for each split.

For the data containing the whole marker set, the average accuracy of the classifier is $89 \%$ in the case of the five-fold cross-validation and $87 \%$ for the three-fold one. After the removal of the "state consistent" marker, we achieved $93 \%$ and $87 \%$, respectively. The most important features turned out to be the same in all iterations of the validation procedure. However, their relative importance was slightly different from those presented in Tables 4 and 6.

\subsection{Towards a Robust Classifier}

From the above results, it follows that decision trees may indeed be used as a tool supporting experts in the process of art authentication. First of all, they may help to summarize the partial outcomes of individual investigation steps. Moreover, they allow for identifying the most significant attribution markers based on the available data. This is of particular importance if there are some budget or time constraints for the analysis, since the experts may then focus only on the decisive investigation procedures.

The preliminary results for classification are also very promising, despite the fact that we used one of the simplest methods among the available algorithms, and we did not put a lot of effort into its optimization. The overall accuracy close to $90 \%$ was very good. However, a closer look at the predictions of the classifier (Table 5) revealed that its recall, which measured the fraction of important instances among the retrieved ones, was low for forged paintings. This was simply due to the fact that our dataset was unbalanced, with much more instances of authentic paintings.

Larger datasets with more balance between the classes are required to build better classifiers. However, then one would probably go for more advanced classification algorithms known to have better performance than these decision trees (e.g., random forests or neural networks; see Reference [45] for review).

\section{Conclusions}

In this paper, we studied the applicability of a method combining attribution markers [39] with the decision trees [19] for the authenticity assessments of paintings. Decision trees are a machine learning algorithm, which is very easy to interpret even by people with no prior expert knowledge from the IT and math domains. Due to this, they are often 
used as a decision supporting tool. When applied to attribution markers, decision trees should assist in: (a) the identification of the important markers, (b) establishing the relative relevance of the markers and (c) a prediction of authenticity of a new painting with known values of the markers. From our analysis, it follows that decision trees indeed meet all of our expectations and may be used as a tool supporting art experts.

With the help of a decision tree trained on a subset of 46 paintings (including 36 authentic ones), we were able to identify the important attribution markers and to establish their rankings. Interestingly, the "state consistent" marker, indicating the overall impression of an art expert about the painting, turned out to be the most important one. This finding is in line with the results in the assisted diagnostics [45].

The resulting decision tree was also checked as a classifier; it was able to identify the authenticity of the paintings in the test set (nine paintings-among them, two forged) with an accuracy of $88 \%$. However, even if one does not trust the classification capabilities of the algorithm, the method can still be used to summarize the available data. Having a summary in the form of an easy-to-read tree-like structure, the actual decision on an investigated painting should be much easier to accomplish.

As already mentioned in the previous section, larger sets of good quality training data will be required for the development of more robust classifiers.

Supplementary Materials: The following supporting information are available online, Table S1. The list of the analysed paintings.

Author Contributions: Conceptualization B.I.Ł.-K.; methodology, B.I.Ł.-K. and J.S.; software, J.S.; validation, J.S.; formal analysis, J.S.; investigation B.I.Ł.-K.; resources, B.I.Ł.-K.; data curation, B.I.Ł.-K. and J.S.; writing-original draft preparation, B.I.Ł.-K. and J.S.; writing-review and editing, B.I.Ł.-K. and J.S.; visualization, B.I.Ł.-K. and J.S.; supervision, B.I.Ł.-K.; project administration, B.I.Ł.-K.; funding acquisition, B.I.Ł.-K. All authors have read and agreed to the published version of the manuscript.

Funding: This research received no external funding.

Institutional Review Board Statement: Not applicable.

Informed Consent Statement: Not applicable.

Data Availability Statement: Not applicable.

Acknowledgments: Barbara Łydżba-Kopczyńska is deeply grateful to Grzegorz Rusek for his scientific guidance and fruitful discussions. The authors acknowledge Anna Klisińska-Kopacz from the Laboratory of Analysis and Non-Destructive Investigation of Heritage Objects (LANBOZ) in Krakow for providing information on her investigation. Barbara Łydżba-Kopczyńska express gratitude to the National Museum in Wrocław, Ossoliński National Institute in Wrocław, National Museum in Warsaw and the National Museum in Kraków for their support and access to their collections. The project "Spectroscopy Investigations of the Painting Technique of Michael Willmann" was funded by Die Deutsch-Polnische Gesellschaft der Universität Wrocław (Breslau), 2007-2010. The project “Authenticity of the Paint Layer in Old-printed Maps from the Niewodniczański Collection of Silesiaca, 16th to 18th century" was funded by the EU, grant agreement 228330, 2011. The study "Dofinansowanie ustalenia atrybucji obrazu Bolko II Świdnicki odnalezionego w klasztorze w Krzeszowie rozstrzygającej autorstwo cyklu fikcyjnych portretów Piastów Śląskich w oparciu o badania fizykochemiczne warsztatu malarskiego Jeremiasa Josepha Knechtla" was supported by the Foundation for Polish Science FNP EX7/2011, 2011-2014. The research of the paintings attributed to A. Grottger was carried out with use of the infrastructure of the Interdisciplinary Centre for Modern Technology of the Nicolaus Copernicus University in Torun financed by the Regional Operational Programme for Kujawsko-Pomorskie Voivodship of the European Regional Development Fund (Project No.: RPKP.05.04.00-04-001/10). The investigations of the painting "Christ in Gethsemane" by M.L. Willmann were caried out by the MOLAB/FIXLAB.PL project of the Polish Research Consortium for Heritage Science (E-RIHS.pl), 2018.

Conflicts of Interest: The authors declare no conflict of interest. 


\section{References}

1. Ehrmann, T. The Contemporary Art Market Report 2016. Available online: https://www.artprice.com/artprice-reports/thecontemporary-art-market-report-2016/contemporary-art-market-2016 (accessed on 20 September 2021).

2. Ehrmann, T.; Wan, J. The Art Market in 2020 by AMMA \& Artprice.com. AMMA (Art Mark Monit Artron). 2020. Available online: https://imgpublic.artprice.com/pdf/ / the-art-market-in-2020.pdf (accessed on 20 September 2021).

3. Amineddoleh, L. Purchasing Art in a Market Full of Forgeries: Risks and Legal Remedies for Buyers. Int. J. Cult. Prop. 2015, 22, 419-435. [CrossRef]

4. Maslin; Nir, S.; Cohen, P.; Rashbaumaug, W.K. Struggling Immigrant Artist Tied to $\$ 80$ Million New York Fraud. New York Times, 17 August 2013; p. 1.

5. $\quad$ Fleming, S.J. Authenticity in Art: The Scientific Detection of Forgery; Institute of Physics: Bristol, UK, $1975 ;$ p. 164.

6. Craddock, P. Scientific Investigation of Copies, Fakes and Forgeries; Elsevier: Amsterdam, The Netherlands, 2009 ; p. 628.

7. Blumberg, N. Wolfgang Beltracchi. In Encyclopedia Britannica. Available online: https://www.britannica.com/biography/ Wolfgang-Beltracchi (accessed on 20 September 2021).

8. Birkenstock, A. Beltracchi-Die Kunst der Fälschung; Fruitmarket Kultur und Medien GmbH: Cologne, Germany, 2014.

9. Wolters, C. Die Bedeutung der Gemälde Durchleuchtung mit Röntgenstrahlen für Die Kunstgeschichte Dargestellt an Beispielen aus der Niederländischen Unddeutschen Malerei des 15. Und 16. Lichtungen zur Kunstgeschichte; Frankfurt am Main Prestel Verlag: Frankfurt, Germany, 1938.

10. De Wild, A.M. The Scientific Examination of Pictures; An Investigation of the Pigments Used by the Dutch and Flemish Masters from the Brothers Van Eyck to the Middle of the 19th Century; G. Bell \& Sons Ltd.: London, UK, 1929; p. 121.

11. Keen, P.G.W. Decision Support Systems: An Organizational Perspective; Massachusetts Institute of Technology: Cambridge, MA, USA, 1980; p. 50.

12. Garg, A.X.; Adhikari, N.K.J.; McDonald, H.; Rosas-Arellano, M.P.; Devereaux, P.J.; Beyene, J.; Sam, J.; Haynes, R.B. Effects of computerized clinical decision support systems on practitioner performance and patient outcomes: A systematic review. J. Am. Med. Assoc. 2005, 293, 1223-1238. [CrossRef] [PubMed]

13. Hand, D.J.; Henley, W.E. Statistical classification methods in consumer credit scoring: A review. J. R. Stat. Soc. Ser. A Stat. Soc. 1997, 160, 523-541. [CrossRef]

14. Samuel, A.L. Some Studies in Machine Learning. IBM J. Res. Dev. 1959, 3, 210-229. [CrossRef]

15. Kotsiantis, S.B. Supervised Machine Learning: A Review of Classification Techniques. Informatica 2007, 31, 249-268.

16. Awad, W.; Elseuofi, S.M. Machine Learning Methods for Spam E-Mail Classification. Int. J. Comput. Sci. Inf. Technol. 2011, 3, 173-184. [CrossRef]

17. Fawcett, T.; Provost, F. Combining Data Mining and Machine Learning for Effective User Profiling. KDD $1996,8-13$.

18. Wu, R.S.; Ou, C.S.; Lin, H.Y.; Chang, S.I.; Yen, D.C. Using data mining technique to enhance tax evasion detection performance. Expert Syst. Appl. 2012, 39, 8769-8777. [CrossRef]

19. Safavian, S.R.; Landgrebe, D. A survey of decision tree classifier methodology-Systems, Man and Cybernetics. IEEE Trans. Syst. Man Cybern. 1991, 21, 660-674. [CrossRef]

20. Ellen, D.; Day, S.; Davies, C. Scientific Examination of Documents: Methods and Techniques, 4th ed.; CRC Press: Boca Raton, FL, USA, 2018; p. 266.

21. Ciesla, R.; Trzciński, M.; Szwagrzyk, K.; Drawc, M. Interdisciplinary examination of documents of historical significance. Int. J. Conserv. Sci. 2020, 11, 669-678.

22. Cieśla, R. Questioned document examination with the use of alternative and complementary non-destructive methods. Nowa Kodyfikacja Prawa Karnego 2021, 57, 149-167. [CrossRef]

23. Ciba, M.; Kozieł, A.; Łydżba-Kopczyńska, B. Obrazy Michaela Willmanna Pod Lupa; Kozieł, A., Ed.; Muzeum Regionalne w Jaworze: Jawor, Poland, 2011; pp. 1-111.

24. Łydżba-Kopczyńska, B. Chemia obrazu: Badania spektroskopowe obrazu “Św. Jan Kapistran” Michaela Leopolda Willmanna. In Fides et Scientia: Wokót Obrazu Michaela Leopolda Willmanna Św Jan Kapistran; Muzeum Miejskie Wrocławia: Wrocław, Poland, 2011; pp. 133-141.

25. Woźny, Ł. Ocena Zakresu Zastosowania Metod Mikroskopowych i Spektroskopowych w Badaniach Pigmentów i Spoiw Malarskich. Master's Thesis, University of Wrocław, Wrocław, Poland, 2015.

26. Łydżba-Kopczyńska, B.; Iwanicka, M.; Kowalska, M.; Targowski, P. Combining macro-XRF, OCT, and sampling techniques in the authentication study of the painting attributed to Michael Willmann. X-ray Spectrom. 2021, 50, 384-400. [CrossRef]

27. Frączek, P.; Klimek, A.; Klisińska-Kopacz, A.; Łydżba-Kopczyńska, B.; Obarzanowski, M. Report of National Center for Reseach on Heritage K1-2015-03-Badania Technologiczne Obrazu Pojmanie Samsona ze Zbiorów Muzeum Zamkowego w Pszczynie dla Muzeum Zamkowego w Pszczynie; National Museum in Kraków: Kraków, Poland, 2017; pp. 1-180.

28. Ciba, M.; Łydżba-Kopczyńska, B. Technika malarska Jeremiasa Josepha Knechtla na podstawie badań fizykochemicznych obrazu Św. Karol Boromeusz z kościoła filialnego pw. św. Wawrzyńca w Przychowej. In Jeremias Joseph Knechtel (1679-1750) Legnicki Malarz Doby Baroku; Muzeum Miedz: Legnica, Poland, 2012; pp. 69-84.

29. Łydżba-Kopczyńska, B. Raman Spectroscopy Applied to the Analysis of Typomorphic Minerals in Various Provenance Investigations of Cultural Heritage Objects. In Raman Spectroscopy in Archaeology and Art History, 2nd ed.; Vandenabeele, P., Edwards, H., Eds.; Royal Society of Chemistry: London, UK,, 2019; Volume 2, pp. 289-313. 
30. Łydżba-Kopczyńska, B.; Targowski, P.; Iwanicka, M. MACRO-XRF scannig and optical coherence tomography (OCT) techniques for the authentification of selected artworks. In Third International Congress on Chemistry for Cultural Heritage; Vienna University of Technology: Vienna, Austria, 2014; pp. 19-192.

31. Bastek, G.; Łydżba-Kopczyńska, B.; Pilecka-Pietrusińska, E.I.M.S. Święta Rodzina ze świętym Janem Chrzcicielem i świętą Katarzyna Aleksandryjską Gianfrancesca Penniego: Badania technologiczne wersji z Warszawy i Bostonu/Technological Examination of the Warsaw and Boston Versions of The Holy Family with Saint John and Sa. Rocz Muz Nar w Warszawie Nowa Ser. J. Natl. Mus. Wars. New Ser. 2014, 3, 151-195.

32. Łydżba-Kopczynska, B.; Czop, J.; Fraczek, P.; Klisinska-Kopacz, A.; Walczak, M.; Obarzanowski, M. The potentaial of interconnected X-ray techniques in the atribution investigations- “The Ecstasy od Saint Francis” by El Greco. In Book of Abstract 3rd International Conference on Innovation in Art Research and Technology-INART; University of Parma: Parma, Italy, 2018; pp. 158-159.

33. Łydżba-Kopczyńska, B. Report of National Museum in Krakow, El Greco, Ekstaza Św. Franciszka "Badania Przekrojów Porzecznych Próbek Malarskich z Zastosowaniem SEM-EDS"; National Museum in Krakow: Kraków, Poland, 2016; pp. 1-74.

34. Łydżba-Kopczyńska, B.; Klisińska-Kopacz, A.; Mendys, A.; . Frączek, P.; Obarzanowski, M.; Czarnecka, M. Scientific examination of a newly discovered painting by Bosch. In Proceedings of the 4th International Congress on Chemistry for Cultural HeritageCHEMCH2016, Brussels, Belgium, 6-8 July 2016.

35. Łydżba-Kopczyńska, B.; Cartecchini, L.; Doherty, B.; Anselmi, C.; Buti, D.; Grazia, C.A.R. Noninvasive in situ study of the authenticity of the paint layer in old-printed maps from the Niewodniczański Collection of Silesiaca (Poland) 16th to 18th century. In Proceedings of the 2nd International Congress of Chemistry for Cultural Heritage (ChemCH) Istanbul, Istanbul, Turkey, 8-11 July 2012.

36. Zygier, E.; Klisińska-Kopacz, A.; Fraczek, P. Analiza technologii malarskiej Maksymiliana Gierymskiego z wykorzystaniem nieinwazyjnych technik badawczych na przykładzie obrazu, Jabłoń nad potokiem. Opusc. Musealia 2016, $23,4560$.

37. Sarkowicz, D.; Sieklucka, M. The application of modern analitical techniques in the investigation of the large scale painting Nero's torches by Henryk Siemiradzki. Opusc. Musealia 2016, 23, 8399.

38. Sarkowicz, D.; Klisińska-Kopacz, A. Investigation of the Painting Idyll Attributed to Henryk Siemiradzki: The Unusual Technology of a Canvas Painting Executed on an Enlarged Photograph. Stud. Conserv. 2018, 63, 251-266. [CrossRef]

39. Edwards, H.G.M.; Vandenabeele, P. Analytical Archaeometry. Selected Topics; Edwards, H.G.M., Vandenabeele, P., Eds.; The Royal Society of Chemistry: Cambridge, MA, USA, 2012; p. 569.

40. Łydżba-Kopczyńska, B.; Ciba, M.; Rusek, G. Implementation of scientific methods of fine art authentication into forensics procedures: The case study of "Bolko II Świdnicki" by J. J. Knechtel. In Proceedings of the 7th International Congress on the Application of Raman Spectroscopy in Art and Archaeology, Ljubljana, Slovenia, 2-6 September 2013; Ropret, N.O.P., Ed.; Institute for the Protection of Cultural Heritage of Slovenia: Ljubljana, Slovenia, 2013; pp. 198-199.

41. Stolper, E.; Van De Wiel, M.; Van Royen, P.; Van Bokhoven, M.; Van Der Weijden, T.; Dinant, G.J. Gut feelings as a third track in general practitioners' diagnostic reasoning. J. Gen. Intern. Med. 2011, 26, 197-203. [CrossRef] [PubMed]

42. Frank, E.; Hall, M.A.; Witten, I.H. The WEKA Workbench. Online Appendix for “Data Mining: Practical Machine Learning Tools and Techniques", 4th ed.Morgan Kaufmann: Burlington, MA, USA, 2016.

43. Van Rossum, G.; Drake, F.L. Python 3 Reference Manual; CreateSpace: Scotts Valley, CA, USA, 2009; Volume 22, pp. 9117-9129.

44. Pedregosa, F.; Varoquaux, G.; Gramfort, A.; Michel, V.; Thirion, B. Scikit-learn: Machine Learning in Python. J. Mach. Learn. Res. 2011, 12, 2825-2830.

45. Raschka, S. Python Machine Learning; Packt: Birmingham, UK, 2015. 